\title{
Priority Setting in Surgical Management of Breast Abscess in Newborn: Case Report
}

\section{B Hamillour*}

Pediatric Surgeon, Department of Surgery, Maghlaoui Brothers Hospital, Mila, Algeria

*Corresponding Author: B Hamillour, Pediatric Surgeon, Department of Surgery, Maghlaoui Brothers Hospital, Mila, Algeria. Email: hamillour.bochra@gmail.com DOI: $10.31080 /$ ASMS.2020.04.0700
Received: June 30, 2020

Published: July 28, 2020

(C) All rights are reserved by B Hamillour.

\section{Abstract}

Neonatal breast enlargement often occurs during the neonatal period is a common response which occurs under the influence of falling levels of maternal estrogen at the end of pregnancy [1]. This situation takes place in both sexes without prevalence, with sometimes milk secretion [4]. Spontaneous resolution requires reassuring parents [1-4].

Mastitis or abscess of the breast in the newborn is a rare condition which is observed in $5 \%$ of cases [3]. Staphylococcus aureus is the bacterium commonly responsible for all major of breast abscess [11].

Ultrasonography as an essential non-invasive diagnostic approach is well recognised as a first-line examination in the setting of breast abscess [6].

Our case illustrates the importance of rapid surgical management as a compliment to medical treatment and the ideal time to undertake surgical breastfeeding in order to avoid serious complications as generalized sepsis breast hypoplasia, and scarring [11]. Keywords: Mastitis; Newborn; Breast Abscess; Surgery

\section{Introduction}

Neonatal abscess is an uncommon condition; few cases are reported per year at most [1]. Generally this disorder needs to be diagnosed early and treated promptly with antibiotics. However, surgical management must be in command moment to avoid the potential severe complications as osteomyelitis, fasciitis, cellulitis, and generalized sepsis [4-9].

We report a recent case of neonatal breast abscess, which was successfully treated with combined medical and surgical management [7-9].

\section{Case Report}

A 28-day-old male infant was referred from a peripheral hospital with swelling over the left breast (Figure 1).

He was delivered vaginally at full term and did not require a prolonged nursery stay or antibiotic therapy. With swelling over the right side of the chest suggestive of abscess. This was associated with high-grade fever and excessive crying. There was no reported history of trauma. The child had a history of breast massage to express the secretions and fomentation to decrease the mass has been implicated by several authors. There was no history suggestive of umbilical sepsis or perinatal catheterisation. The rest of

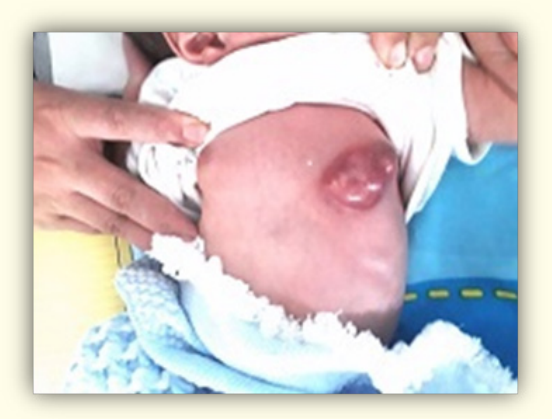

Figure 1: Neonatal left breast abscess.

the clinical examination revealed an adequately nourished infant without anomaly.

Ultrasonography of the thorax was suggestive of abscess in the left breast and cortical regularity of the ribs; however, the lung fields were without anomaly.

Complete blood picture revealed total leucocyte count of 27 $\times 10^{3} / \mathrm{L}$ with peripheral smear showing $62 \%$ neutrophils. Ultrasensitive $\mathrm{C}$ reactive protein (CRP) was $>160.7 \mathrm{mg} / \mathrm{L}$. Incision and drainage was performed (Figure 2). Blood culture, as well as pus 
culture, revealed Staphylococcus aureus sensitive to, amikacin, cotrimoxazole, cloxacillin erythromycin, gentamycin, tetracycline/ doxycycline, clindamycin, ciprofloxacin/ofloxacin, but resistant to amoxicillin-clavulanic acid. Patient was discharged in good condition after 10 days of admission. The patient showed up for followup after one week there was complete resolution of abscess (Figure 3).

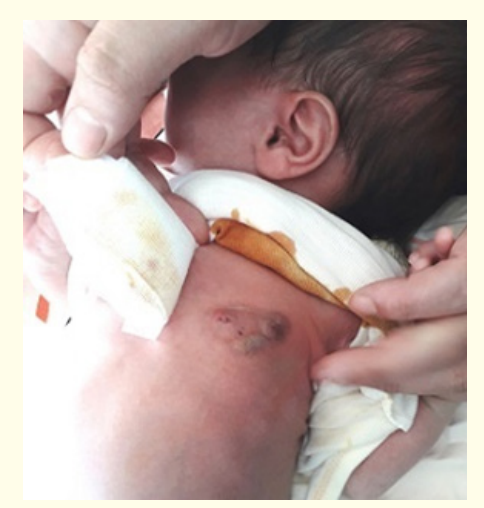

Figure 2: Aspect of breast abscess after drainage.

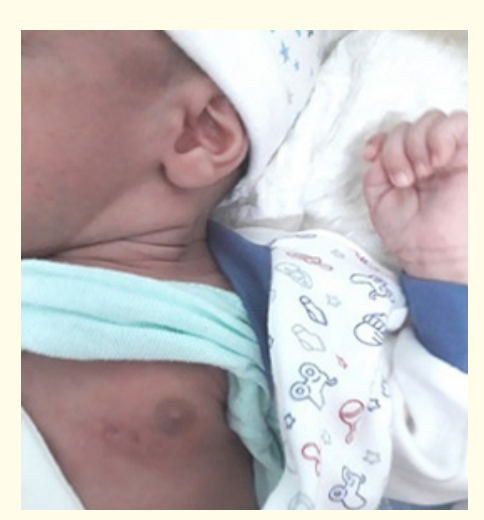

Figure 3: Right breast with full recovery.

\section{Discussion}

Neonatal breast enlargement has been reported to occur in 65 - $90 \%$ of infants; is a benign condition that may be seen during the first days of life in the neonatal period [1,2].

It usually involutes, and later regrows during puberty due to hormonal stimulation [3-5].

The breast tissue is originating from ectodermal and epidermal elements, appears around the fifth week of gestation [3,9]. First the mammary buds that persist in the thoracic region penetrate the underlying mesenchyme and give rise to several secondary buds which develop into lactiferous ducts and their branches.
These are canalized by the end of the prenatal life [3].

The maturation of its cannulas as well as the glandular tissue occurs around the 28 week of under the effect of estrogen and progesterone [2].

There is no proper terminology to describe uncomplicated, physiological enlargement of breasts in the newborn; many term are used to describe, various forms of breast swellings in newborn such as: physiological enlargement, exaggerated development, bulging galactocele, inflammatory swelling and breast abscess, Mastitis, galactorrhea, gynecomastia, galactocele, breast hypertrophy and breast enlargement have been used interchangeably to denote any of the aforementioned presentations. Notoriously, hardness $[1,7]$.

Breast abscess, a more common condition in newborns than in older children. It usually develop in full-term infants during the first 6 weeks of life; about 84\% develop in the first 3 weeks. Boys and girls are also affected on departure [2].

It rarely affects premature infants because breast tissue is underdeveloped. Maternal endocrinopathy was noted in 0 to $14 \%$ of cases $[2,4]$.

The clinical diagnosis of breast abscess associates breast enlargement and varying degrees of pain, erythema, firmness, and fluctuance. This most often affects a single breast. There is no side predilection but bilateral forms were described in less than $5 \%$ of cases [5].

When mastauxe becomes true abscess?

Is difficult to say with certainty because they often share the same physical signs, which justifies strict monitoring between neonatology and surgeon [5-11].

The literature review reveals that most of the breast abscess cases due to Staphylococcus aureus wish was the case in our patient, but infections with Streptococci, Proteus mirabilis, Escherichia coli, Salmonella and Pseudomonas aeruginosa have been reported [11].

Systemic manifestations are generally rare (8 to 28\%), according to Ruwaili and Scolnik [4].

50 to $70 \%$ of them progress to become breast abscess requiring needle aspiration or surgical drainage of pus. About 30 to $60 \%$ of the neonates needed hospital admission for intravenous antibiotics or surgical treatment [5-9]. 
Ultrasonography can be an indispensable tool in breast abscess especially to look for complication; but often the clinical breast examination is enough to make the diagnosis $[4,5]$.

First-line treatment for breast abscess combines general antibiotic therapy (amoxicillin and clavulanic acid; or erythromycin; clindamycin) According to the antibiogram test with a puncture or small incision $[7,11]$.

Serious life-threatening and systemic complications such as cerebral abscess have been documented in the literature [8,9]. Brain abscess due to Staphylococcus aureus following neonatal breast abscess: case report and a brief review of the literature [8].

Generally systemic manifestations are rare just as critical lifethreatening: cerebral abscess, osteomyelitis have been documented in the literature.

Ruwaili and Scolnik noted that approximately one half of neonatal mastauxe is complicated by mastitis and one half of neonatal mastitis progresses to become frank abscess. Neonatal mastitis showed cluster occurrence in Brett's series [8].

\section{Conclusion}

Through this case report it is intended to highlight the fact that surgical drainage should be the first line treatment for breast abscesses in new born, in order to avoid the most serious complications, namely cellulite, osteomyelitis and septic. Early care is imperative.

\section{Bibliography}

1. Amer A and Fischer H. "Neonatal breast enlargement". The New England Journal of Medicine 360 (2009): 1445.

2. T Stricker., et al. "Mastitis in Early Infancy". Acta Paediatrics 94.2 (2005): 166-169.

3. Asma Javed. "Development of the Human Breast". Plastic Surgery 27.1 (2013): 5-12.

4. Talat Masoodi., et al. "Neonatal Mastitis: A clinic Microbiological study". Journal of Neonatal Surgery 3 (2014): 2.

5. Juan Jesús Pérez-Guerrero., et al. "University Hospital Puerta del Mar, Spain”. Annals of Clinical Case Reports (2017).

6. Eun Ji Lee., et al. "Breast Lesions in Children and Adolescents: Diagnosis and Management". Korean Journal of Radiology 19.5 (2018): 978-991.
7. Fortunov RM., et al. "Evaluation and treatment of communityacquired Staphylococcus aureus infections in term and latepreterm previously healthy neonates". Pediatrics 120 (2007): 937-945.

8. F Desruelles., et al. "Neonatal staphylococcal breast dermohypodermitis". Annales de Dermatologie et de Vénéréologie 127.6-7

9. Faden H. "Mastitis in children from birth to 17 years". The Pediatric Infectious Disease Journal 24 (2005): 1113.

10. Arunagirinathan A., et al. "Bilateral breast abscess in a neonate - A case report". International Journal of Case Reports and Images 2.5 (2011): 26-28.

11. Nahar AL. "Ruwaili Neonatal mastitis: Controversies in management". Clinical Journal of Neonatalogy 1.4 (2013): 207-210.

\section{Assets from publication with us}

- Prompt Acknowledgement after receiving the article

- Thorough Double blinded peer review

- Rapid Publication

- Issue of Publication Certificate

- High visibility of your Published work

Website: www.actascientific.com/

Submit Article: www.actascientific.com/submission.php Email us: editor@actascientific.com

Contact us: +919182824667 